\title{
Analysis and Utilization of Waste Heat from Marine Diesel Engine Zhiqiang Zhao ${ }^{1, a}$ and WeiZhai ${ }^{2, b}$

\author{
Binzhou Vocational College, Binzhou, Shandong Province 256600
}

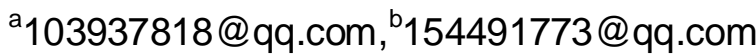

Keywords: Marine diesel engine; Waste gas; Waste heat; Utilization

\begin{abstract}
Energy is an important issue in the development of economical economy in China. In shipbuilding industry, the waste heat utilization of diesel engine is an important technology. This article briefly introduces the definition of waste heat and analyzes the waste heat of hip diesel engine exhaust gas through the six s50me - C8 type diesel engine waste heat utilization system, and then elaborates on the prospect for the development of the main application of this technology and its application in the future.
\end{abstract}

\section{Introduction}

As a kind of energy economy, Marine diesel exhaust waste heat utilization technology is a very important technology. Because of the waste heat utilization technology in China starts relatively late, so the overall development is relatively backward. But in recent years, with the constant improvement of the state on energy conservation importance, a lot of research results have been made in the use of waste heat. Ship diesel engine exhaust gas residual heat analysis and the use of environmental equipment are closely related, therefore the utilization and analysis of waste heat should be according to the specific situation, thus improving heat efficiency.

\section{Status of Waste Heat from Marine Diesel Engine}

In order to further study of Marine diesel engine waste heat utilization, the first step is to determine what waste heat is, and understand the industry of marine diesel engine waste heat utilization in order to carry out relevant researches with targets.

Concept of Waste Heat. Broadly speaking, the heat refers to the heat that can be used and released during the industrial production process when the equipment itself or a specific process completes the release. In particular, these waste heat include exhaust gases generated at high temperatures. The waste heat is used again, for example, for the production of steam to promote the conversion of thermal energy and mechanical energy, heating or urging equipment for production [1].

The use of waste heat is usually divided according to the quality grade. High-quality waste heat is usually used to promote the mechanical equipment to generate power, so as to ensure the utilization of waste heat; low-quality waste heat can usually be used to accumulate heating and heating. If necessary, two kinds of methods can be combined together in actual use [2]. This kind of use can be adjusted according to the actual situation of waste heat so as to ensure the use of quality, improve the efficiency of waste heat utilization, and truly achieve the purpose of saving energy and protecting the environment.

Current Research. China's marine diesel engine waste heat utilization technology research started late, compared to the application level of developed countries and has a big gap. With the popularization of the economical mode of economic development, the research on the waste heat utilization of marine diesel engine has made some progress and got some research results. In 2008, a ship diesel engine company in Dalian produced the first domestic heat recovery system of diesel engines through research, and the model is 7RTA84TD diesel engine [3]. The power of the diesel system is 29,400 kilowatts. In the technical use of Wartsila waste heat recovery technology, and according to the practical application to make a certain simplification, to remove the original plan of the power turbine structure. So this way the heat generated less heat, but for the boiler steam power generation or for the use of ships. Although the recovery system at this time in the heat utilization rate is not high, but for China's waste heat recovery system development is already a huge step forward. The specific structure of the system using dual 
pressure waste heat boiler, including low pressure evaporator, high pressure evaporator and high pressure super heater three parts. When the system load is greater than $55 \%$, it can produce $1100 \mathrm{~kW}$ of electricity [4]. At present, the system has been combined with Singapore's technology for further development and can also improve efficiency in terms of waste heat recovery.

In the early 1990s, a comprehensive transformation of diesel engine waste heat power generation system was carried in China's Guangdong Province. Through further development, waste heat power generation can reach about $4 \%$ of diesel generating units. And the recovery of waste heat is used for air conditioning refrigeration. In terms of the heat, it can guarantee a range of using air conditioning project.

\section{Waste Heat Utilization Device and Performance Calculation of Marine Diesel Engine}

The main structure of 6S50ME-C8 diesel engine waste heat utilization system is composed of ultra-low temperature exhaust waste heat boiler, power turbine, multi-stage double-pressure steam turbine, organic working cycle power generation system, alternator and water supply preheating system. The device uses the heat of the cylinder cooling water and the air cooler to heat the water in the boiler at the same time to recover the low-temperature energy of the exhaust gas as the main source of heat for the organic working cycle and the part of the energy of the exhaust to power turbines for power generation, access to the power of energy can also meet the use of fuel consumption.

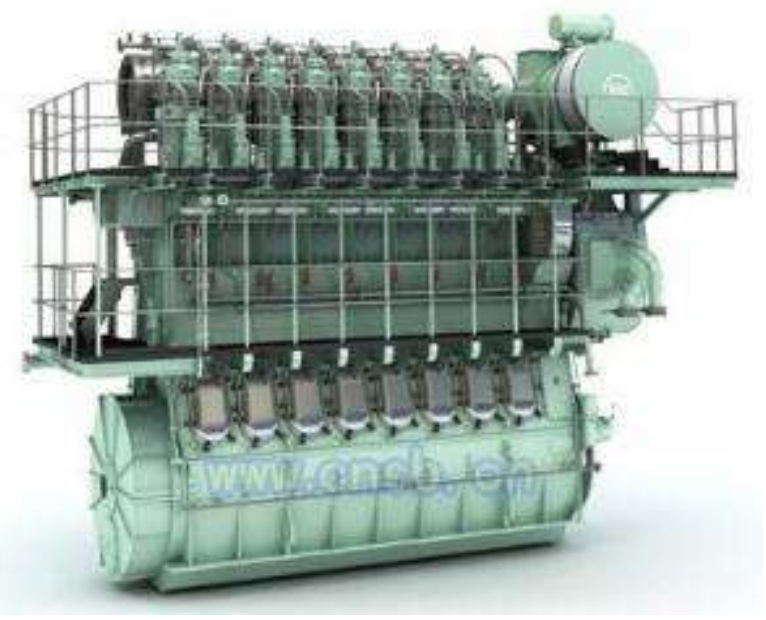

Figure. 1 6S50ME-C8 diesel engine diagram

Waste Heat Utilization Device. Ultra - low Temperature Exhaust Waste Heat Boiler.Ultra-low temperature exhaust heat boiler is mainly composed of vertical flue with a flue, flue source for the waste heat boiler conventional section and ultra-low temperature exhaust section. The boiler is forced to circulate in a horizontal manner by placing a water pipe on the heat transfer heating surface. Heating surface mainly contains high pressure super heater, high pressure evaporator, low pressure evaporator and water heater composition. The boiler is constructed in a double-row polyline form and sometimes with other arrangements that utilize the heat transfer with the evaporator and the recovery of the condenser to avoid the acid corrosion caused by the condensed liquid produced in the conventional section of the ultra-low temperature exhaust heat boiler condensate recovery [5].

During the operation, the host through the exhaust gas to the power turbine and exhaust turbo supercharger for work, after the exhaust gas into the ultra-low temperature exhaust heat recovery boiler, when the flue gas outlet temperature can reach 95 degrees Celsius. The water in the boiler is driven by pressurization of the pump through the main tank cylinder water heat exchanger and the two-stage air cooler high temperature section, so the water temperature to 160 degrees Celsius [6]. After being heated, some of the water enters the high-pressure drum and the other part enters the low-pressure drum.

After the hot water supply, the pressure of the high pressure part of the evaporator can reach $0.7 \mathrm{MPa}$, the structure of the saturated temperature of $143.6{ }^{\circ} \mathrm{C}$. At this time, part of the heat can be used for heating the main engine, the other part can be used as steam turbine steam with the transformation of mechanical energy, thus completing the use of waste heat [7]. 
Steam Turbine.Through the role of waste heat, the use of steam turbine speed of $6750\left(\mathrm{r} \cdot \mathrm{min}^{-1}\right)$ of the double-pressure steam turbine. The high pressure portion of the inlet pressure of the apparatus is $0.7 \mathrm{MPa}$ and the low pressure portion is $0.4 \mathrm{MPa}$. Steam turbine by reducing the role of gear box, connected with the generator, the speed down to the generator speed, $1800\left(\mathrm{r} \cdot \mathrm{min}^{-1}\right)$.

Power Turbines.One tenth of the exhaust energy of the main engine can be used for the use of power turbines so that power turbines and steam turbines can drive the motor together by heat to drive. The relationship between the power turbine and the steam turbine through a certain structure, the specific structure is the reduction gear and over speed clutch, the role of these two structures can ensure that the power turbine in the course of use to avoid the generator jump speed [8]. When the host system load situation When the host load is greater than $55 \%$, this time the power turbine began to function, the host exhaust gas can be used to promote the turbocharger and power turbine equipment, the exhaust can also be through the exhaust pipe Promote the control of the throttle control panel. When the host load is less than $55 \%$, the exhaust volume of the system is low, and the exhaust gas can only act on the turbocharger and cannot drive the power turbine.

Organic Working Power Generation System.The organic working power generation system is mainly composed of liquid storage tank, evaporator, organic working fluid turbine, condenser and generator. Marine waste heat generated by the diesel engine can be heated to $140{ }^{\circ} \mathrm{C}$, hot water through the evaporator, you can produce high temperature and high pressure of organic refrigerant, so as to start the organic work steam turbine work, complete thermal and mechanical energy conversion, thus driving power Machine for power generation.

System Performance Calculation. According to the characteristics of 6S50ME-C8 diesel engine and the existing technology of waste heat utilization of marine diesel engine, the performance of waste heat utilization system is analyzed and the relevant data are calculated. The calculation results of each data are shown in Table 1 . In the data sheet can be seen, the waste heat utilization system can produce $897 \mathrm{~kW}$ of power, equivalent to $12.5 \%$ of the host power, the use of the system heat can make the system thermal efficiency increased by $6.03 \%$.

Table 1 Residual Heat Utilization System Performance Calculation Results

\begin{tabular}{ll}
\hline Item & Value \\
Total Flow of Diesel Exhaust $/\left[\mathrm{kg} \cdot \mathrm{h}^{-1}\right]$ & 65020 \\
Diesel engine exhaust temperature $/\left[{ }^{\circ} \mathrm{C}\right]$ & 332 \\
Power turbine inlet air temperature $/\left[{ }^{\circ} \mathrm{C}\right]$ & 482 \\
Power turbine exhaust temperature $/\left[{ }^{\circ} \mathrm{C}\right]$ & 332 \\
Power turbine inlet pressure $/[\mathrm{MPa}]$ & 0.37 \\
Power turbine inlet flow $/\left[\mathrm{kg} \cdot \mathrm{h}^{-1}\right]$ & 6699 \\
High pressure superheated steam pressure $/[\mathrm{MPa}]$ & 0.65 \\
High pressure superheated steam temperature $/\left[{ }^{\circ} \mathrm{C}\right]$ & 270 \\
High pressure superheated steam flow $/\left[\mathrm{kg} \cdot \mathrm{h}^{-1}\right]$ & 3395 \\
Low pressure saturated vapor pressure $/[\mathrm{MPa}]$ & 0.4 \\
Low pressure saturated steam temperature $/\left[{ }^{\circ} \mathrm{C}\right]$ & 143 \\
Low pressure saturated steam flow $/\left[\mathrm{kg} \cdot \mathrm{h}^{-1}\right]$ & 610 \\
Residual heat of the boiler $/\left[{ }^{\circ} \mathrm{C}\right]$ & 95 \\
Residual heat of waste heat $/[\%]$ & 75.93 \\
Turbine power generation $/[\mathrm{KW}]$ & 432 \\
Power turbine power generation $[\mathrm{KW}]$ & 308 \\
Quantity of organic working turbines $[\mathrm{KW}]$ & 127 \\
Total power generation $/[\mathrm{KW}]$ & 897 \\
Thermal efficiency is improved $/[\%]$ & 6.03 \\
\hline
\end{tabular}


many ways to use the marine diesel engine waste. This part contains a detailed analysis of the specific application of waste heat, and prospects for future development.

Analysis of Waste Heat Utilization. The usage of marine diesel engine waste heat on the ship mainly includes the following aspects: waste heat heating, waste heat power generation, waste heat refrigeration and waste heat power applications.

Heating of Waste Heat.Direct heating. On the ship, the waste heat of the diesel engine can be used to heat the drinking water and domestic water heating of the crews, reduce other energy consumption; waste heat can be used directly on the engine heating to avoid the engine's cold start; part of the waste heat can be used for heating on board.

Use waste heat to produce fresh water. With the continuous development of the economy, the cause of maritime transport has become more and more developed, and people who have been engaged in maritime transport for a long time have been increasing, and the demand for fresh water has been increasing. Due to the limited use of fresh water resources on the ship, the preparation of fresh water has become an important work on board. The use of waste heat can drive the desalination plant on the ship, thereby increasing access to freshwater resources and achieving considerable economic benefits.

Power Generation from Waste Heat.In the course of the work, the ship diesel engine will be discharged from a large number of high-temperature waste gas waste heat resources, the general waste heat can be used for normal heating use, for the operation of the machine or life needs to be a certain driving force. But the traditional use of the existence of low utilization of the problem, failed to make full use of waste heat. In the ship can also convert the diesel engine waste heat into electrical energy, power and practicality and better transmission, can greatly improve the economic benefits of ship operation [9].

Cooling from Waste Heat.The waste heat of the marine diesel engine can be used in the low temperature waste heat for life heating, this heating equipment is simple, and the economy is better. But the heating received seasonal restrictions, so the waste heat is wasted during the non-heating period. So the heat can also be used as a low-temperature heat source of the heat pump, by increasing the temperature level, you can increase the scope of use, so as to ensure the use of waste heat value [10-11].

Power Application of Waste Heat.Turbocharging technology has undergone a long period of development, the current ship diesel engine system can be mostly waste heat recovery [12]. Recovery also led to the rapid development of small high-speed diesel engine. The heat generated by the diesel engine system can inject high-pressure gas into the cylinder. Under the action of heat, the supercharger is driven to reduce the consumption of the original energy, thus improving the utilization rate of the waste heat of the diesel engine system.

Development Trend.In the future development, the use of marine diesel engine waste heat will be moving towards new ways of utilization and new equipment, etc., and the future waste heat utilization will follow certain principles.

Principles of Using Waste Heat.Waste heat utilization principles contain the following aspects: First, simple and practical, good control. With the development of computer technology and automation technology, the control of the equipment is increasing, and the control precision is also improved. But in terms of our country, in the production equipment should also continue to improve and enhance the performance of equipment; Second, to improve the efficiency of waste heat utilization, the current continuous development of compensation technology will promote the waste heat recycling, and thus improve the utilization of waste heat Purpose; third, the heat transfer medium has been improved [13]. The continuous development of materials science and the continuous development of new materials will promote the continuous improvement of heat transfer medium, so as to further improve the use of waste heat.

New Utilization of Waste Heat.The use of high temperature generated by the heating of water generated by the steam drives the turbine to drive the motor power generation, which forms a gas-steam combined cycle waste heat recycling system. Thermo-acoustic effect is an important basis for refrigeration technology, after the absorption of waste heat through the energy conversion, the elimination of sound energy, can achieve the effect of cooling. The reliability of the thermo-acoustic refrigeration system is higher, so the impact on the environment is small, in line with China's environmental protection 
economic development model.

\section{Conclusion}

In summary, the use of waste heat of marine diesel engine is an important work for energy conservation and emission reduction. In terms of our current recovery system, recycling technology and recycling equipment and materials should also be used to improve, and thus continue to improve the utilization of waste heat utilization. In this study, the waste heat of marine diesel engine waste as the starting point, combined with specific diesel models, analysis of waste heat technology application measures, and finally its future development prospects. It is hoped that through this paper, we will provide experience and reference for similar research and make joint efforts to promote the energy saving and emission reduction of ships in China and realize the purpose of building a harmonious society.

\section{References:}

[1] LI Zongying, YANG Chuanlei, HU Song, YU Encheng, DONG Rijing. Optimum Design of Exhaust Pipe Structure for a Type of Pulse Turbocharged Diesel Engine [J]. Application Technology.2017 (08): 45 .

[2]GE Zeyu. Analysis and Management of Fuel Common Rail System for Marine Electronic Control Diesel Engine [J]. Maritime. 2017(03):87-88.

[3] HUANG Yu. Discussion on Low Nitrogen / Nitrogen Free Combustion Technology for Marine Diesel Engine [J]. Science and Technology Innovation and Application. 2017(23):123.

[4] ZHU Jun, ZHANG Xianhe, GAO Hongliang, YANG Jianguo. Study on Application of Thermal Power Monitoring Technology for Main Bearing Wear of Marine Diesel Engine [J]. Diesel Engine.2017(03):65.

[5] MA Tianshao, MAO Jinlong, ZHANG Wenzheng, PING Tao. Optimization of Diesel Engine Intercooler Flow Uniformity Based on CFD Simulation [J]. Diesel Engine.2017(03):101-102.

[6] LI Mei, WU Xianlei, WU Limin, LANG Gang. Study on Influence of Main Bearing Cover of Marine Diesel Engine on Oil Film Lubrication of Bearing [J]. Diesel Engine.2017(03):87.

[7] CHANG Tie, YANG Puze. Study on Friction Properties of Cylinder Liner Based on Synergistic Effect of Surface Thermal Coating and Surface Texture [J]. Thermal Processing Technology. 2017(14):110.

[8] LIU Haifeng, ZHANG Huixiang, WANG Hu, ZOU Xian. Effects of Intake Components on NO_x Emissions from Low Speed Ship [J]. Combustion Science and Technology.2017(04):93.

[9] WANG Yonghong, TIAN Yongwei, GUO Min, GU Gang, CHENG Zhong. Cause Analysis and Preventive Measures of Pore Defects in Camshaft Shaft Holes of a Marine Diesel Engine [J]. Thermal Processing Technology. 2017(13):28-29.

[10] ZHOU Zibao. The Strength Calculation of Crankshaft Reliability of Outboard Engine [J]. China High - tech Zone.2017(16):63.

[11] Zhou Bi, Zhu Congrong. Numerical Simulation of Exhaust Gas Recirculation System for Diesel Engine [J]. Mechanical Design and Manufacturing.2012(07):92.

[12] HE Youxu. The Arrangement and Inspection of Fuel Heating System for Marine Diesel Engine [J]. Tianjin Maritime.2014(04):112.

[13] Yang Yongdong. Emission Control Technology of Marine Diesel Engine [J]. Global Maritime.2013(03):89. 